Disponível em:

http://editora.unoesc.edu.br/index.php/race

Race, Joaçaba, v. 14, n. 2, p. 707-736, maio/ago. 2015

\title{
RELAÇÃO ENTRE ESTILO DE LIDERANÇA E COMPROMETIMENTO ORGANIZACIONAL AFETIVO
}

\section{Relation between leardeship style and affective organizational commitment}

\section{Maria de Lourdes de Oliveira Nogueira}

E-mail: lourdes.nogueira59@gmail.com

Mestre em Administração com ênfase em Gestão de Pessoas pela Universidade Metodista de São Paulo; Especialista em Administração de Recursos Humanos e Psicologia Organizacional pela Faculdade Hoyler; Professora no Centro Universitário Estácio; Professora nas Faculdades Metropolitanas Unidas.

Luciano Venelli Costa

E-mail: luciano.venelli@gmail.com

Doutor em Administração pela Universidade de São Paulo; Mestre em Administração pela Universidade Metodista de São Paulo; Professor Titular da Graduação e do Mestrado em Administração da Universidade Metodista de São Paulo; Diretor da Faculdade de Administração e Economia.

Endereço para contato: Rua Alfeu Tavares, 149, Rudge Ramos, 09641-000, São Bernardo do Campo, São Paulo, Brasil.

\section{José Alberto Carvalho dos Santos Claro}

E-mail: albertoclaro@albertoclaro.pro.br

Doutor em Comunicação Social pela Universidade Metodista de São Paulo; Mestre em Administração pela Universidade Metodista de São Paulo; Professor Adjunto Nível A.I. de Administração na Universidade Federal de São Paulo - Campus Baixada Santista; Professor credenciado no Programa de Pós-graduação (Mestrado

Profissional) em Gestão de Políticas e Organizações Públicas pela Universidade Federal de São Paulo - Escola Paulista de Política, Economia e Negócios - Campus

Osasco.

Artigo recebido em 18 de setembro de 2014. Aceito em 23 de fevereiro de 2015. 
Resumo

A liderança e seus estilos contribuem para gerar desempenho e resultados melhores para as organizações. Objetivou-se analisar a relação entre os estilos de liderança e o comprometimento organizacional afetivo (COA). Utilizou-se o método quantitativo, com dados coletados por um questionário de autopreenchimento composto por três escalas que medem as variáveis da pesquisa com 92 trabalhadores de uma empresa privada na cidade de São Paulo. A análise foi descritiva e multivariada, buscando-se correlações entre três estilos de liderança: tarefa, relacionamento e situacional com o COA. Encontraram-se fracas correlações entre estilos de liderança e COA, sendo significativas as correlações do comprometimento com o estilo tarefa e com o estilo situacional, porém, com variações em razão do tamanho da amostra. Esses resultados contribuem para o aprimoramento dos processos de gestão de pessoas a fim de promover melhorias no desenvolvimento das lideranças e no comprometimento das pessoas por meio das políticas da organização.

Palavras-chave: Comportamento organizacional. Estilo de liderança. Comprometimento organizacional afetivo. Organização. Gestão de pessoas.

\title{
Relation between leardeship style and affective organizational commitment
}

\begin{abstract}
The leadership and their styles help to generate better outcomes for organizations. This study had the objective to examine the relationship between leadership styles and affective organizational commitment (AOC). We used the quantitative method with data collected by a self-report questionnaire consisting of three scales measuring the variables of the survey of 92 employees of a private company in São Paulo. The analysis was descriptive and multivariate, seeking correlations between three styles of leadership: task, relationship and situational with AOC. It was found weak correlations between leadership styles and AOC, with significant interdependence between commitment to the task with style and situational style, though with variations depending on the sample size. These results contribute to the improvement of management processes of people in order to promote enhancements in the development of leadership and commitment of people through the organization's policies.
\end{abstract}

Keywords: Organizational behavior. Leadership style. Affective organizational commitment. Organization. People management.

\section{INTRODUÇÃO}

O processo de globalização econômica acirrou a competição entre as empresas de tal maneira que aquelas que não alcançam vantagens competitivas perdem espaço para as concorrentes. Em contrapartida, o processo de globalização tem oferecido oportunidade às empresas de se atualizarem tecnologicamente, fabricarem mais 
com custos menores, adquirirem matéria-prima em qualquer parte do mundo e comercializarem seus produtos em condições vantajosas para seus clientes. Ao longo dos 30 anos anteriores a este estudo, autores têm se dedicado ao tema globalização, considerada um processo revolucionário e decorrente dos avanços tecnológicos, que tem afetado a sociedade (MOLLIS, 2008; FURTADO, 2010; WANDERLEY, 2006). As mudanças ocorridas têm estimulado novas práticas de produção, intensificado a comercialização de produtos e serviços e gerado novos conhecimentos. Nesse sentido, as empresas têm sido levadas a promover adaptações em suas formas de gestão, a fim de garantir a própria sobrevivência. Nesse cenário competitivo, algumas empresas alcançam destaque ao buscarem diferenciais entre concorrentes do mesmo setor (PORTER, 1980). Outras encontram em seus recursos internos e diferenciados suas fontes de vantagem competitiva, segundo a visão baseada em recursos - Resource Based View (RBV) (PENROSE; PITELIS, 1959).

Conforme Barney (1989), as empresas não são iguais, pois cada uma delas possui história, cultura, experiências, valores próprios, bem como conhecimento e, com isso, as pessoas vêm ganhando importância no cenário competitivo das organizações. Para que esses diferenciais aconteçam, é necessário que os colaboradores queiram entregar para a organização o seu conhecimento e contribuir com as suas experiências. Essa necessidade faz com que a questão do comprometimento da pessoa com os objetivos organizacionais ganhe importância. Autores definem bases e dimensões sobre o comprometimento, mas o que mais contribui para um melhor desempenho é o comprometimento afetivo (SIQUEIRA, 2008). Mowday, Porter e Steers (1979) definem comprometimento organizacional afetivo como um estado em que o empregado se identifica com a organização, assim como com seus objetivos, e expressa desejo de se manter nela.

Outro fator relevante na busca do diferencial pelas pessoas é o investimento no trabalho dos líderes. Lidar com pessoas é um desafio constante. Valores, ideologias, múltiplas visões esbarram com o modo individual de ser. Relacionamentos exigem respeito, cordialidade, diplomacia, principalmente no momento em que é solicitado debater assuntos polêmicos. Para tanto, cabe ao líder e ao liderado tentar transformar o ambiente profissional no mais acolhedor e harmônico possível, já que tal conduta é benéfica e estimulante. De acordo com Conger e Kanungo (1987), o bom gestor é aquele que possibilita a todos os funcionários o exercício de suas funções de modo mais autônomo e responsável.

Sobre a liderança organizacional, existem diferentes estilos para diferentes liderados ou para diferentes focos gerenciais (McGREGOR, 1980; HERSEY; 
BLANCHARD, 1986; BERGAMINI, 1994). Alguns são mais focados em tarefas e objetivos, outros em relacionamentos saudáveis; outros, ainda, são flexíveis e se adaptam a situações que exigem posturas diferentes. Diante dessas considerações, a questão principal que norteia esta pesquisa é: o estilo do líder tem relação com o comprometimento afetivo dos liderados com a organização?

O objetivo geral desta pesquisa foi analisar a relação entre os estilos de liderança e o comprometimento organizacional afetivo em trabalhadores de uma empresa privada em São Paulo. Esse objetivo desdobra-se nos seguintes objetivos específicos:

a) levantar os estilos de liderança percebidos pelos trabalhadores da organização em relação aos seus superiores imediatos;

b) analisar se cada um dos três estilos de liderança dos superiores imediatos têm relação com o comprometimento organizacional afetivo dos liderados.

Esta pesquisa pauta-se na premissa de que os líderes funcionam como guias emocionais da equipe. Ainda que seja um poder inconsciente, segundo Stefano e Gomes Filho (2003), os líderes têm a responsabilidade de dirigir as emoções dos liderados. Partindo-se dessa premissa, é provável que estilos de liderança situacional e de relacionamento promovam emoções positivas, elevando o nível de comprometimento organizacional afetivo, enquanto líderes focados na tarefa provavelmente não conduzam as emoções e, por consequência, esse estilo não deve ter relação com o comprometimento afetivo.

O presente trabalho pretende trazer uma contribuição para as organizações, à medida que possibilita associar o papel de liderança ao comprometimento afetivo dos colaboradores, fator integrado à identificação e ao sentimento de pertencimento, o que fomenta o desejo de permanecer na empresa e, consequentemente, comportamentos que firmem o compromisso nessa relação. Seus resultados poderão ser válidos para a área de Recursos Humanos, a fim de promover melhorias no desenvolvimento das lideranças e no comprometimento das pessoas por meio das políticas da organização; portanto, a base teórica é pautada pelo entendimento da relação da liderança e seus estilos com o comprometimento organizacional afetivo.

Nesta pesquisa, é considerado líder aquele para quem a pessoa pesquisada está subordinada. Os estilos de liderança podem ser definidos como as atitudes de um líder na relação com os seus liderados. No texto foram analisados três fatores como estilos 
de liderança: Tarefa, Relacionamento e Situação (MELO, 2004). Liderança pode ser definida, também, como um processo de influência, comumente de uma pessoa, por meio do qual um indivíduo ou grupo é orientado para o estabelecimento ou o cumprimento de metas. Esses objetivos podem ser alcançados de diferentes maneiras, resultando em diversos tipos de lideranças, permitindo, inclusive, que vários tipos de lideranças operem ao mesmo tempo (BOWDITCH; BUONO, 2002).

Melo (2004) analisou a evolução das abordagens de liderança organizacional e verificou que a atuação da gerência se volta para três focos: tarefa, relacionamento e situacional. Com base nessa constatação, o autor elaborou uma definição constitutiva desses fatores visando demarcar o campo conceitual de cada um deles, os quais ficaram constituídos (Quadro 1):

Quadro 1 - Fatores de liderança

\begin{tabular}{|l|l|}
\hline Fator & Conceito \\
\hline Tarefa & $\begin{array}{l}\text { Refere-se à probabilidade que o líder tem de definir e estruturar o seu } \\
\text { papel e aquele dos subordinados na busca da realização de metas. O líder } \\
\text { enfatiza o trabalho, os aspectos técnicos da função, a observância aos } \\
\text { padrões, os canais de comunicação, a hierarquia, os procedimentos e os } \\
\text { métodos, bem como a realização de tarefas. }\end{array}$ \\
\hline $\begin{array}{l}\text { Relaciona- } \\
\text { mento }\end{array}$ & $\begin{array}{l}\text { Refere-se à extensão em que o líder terá relações de trabalho que sejam } \\
\text { caracterizadas por confiança mútua, amizade, calor humano nas relações, } \\
\text { respeito pelas ideias dos subordinados e interesses pelos seus sentimentos. } \\
\text { O líder valoriza a individualidade e enfatiza as relações interpessoais, como } \\
\text { apoio, orientação e facilitação. }\end{array}$ \\
\hline Situação & $\begin{array}{l}\text { Refere-se à habilidade do gerente em identificar a realidade do seu ambiente } \\
\text { de trabalho e em adaptar o seu estilo às exigências desse ambiente. O líder } \\
\text { é flexível para variar o seu comportamento de acordo com as necessidades } \\
\text { e motivos dos subordinados. A Liderança Situacional baseia-se em uma } \\
\text { inter-relação entre (1) o comportamento do líder voltado para a tarefa, (2) o } \\
\text { comportamento do líder voltado para o relacionamento e (3) a capacidade e } \\
\text { disposição dos subordinados para realizarem as tarefas (maturidade). }\end{array}$ \\
\hline
\end{tabular}
Fonte: Melo (2004).

Segundo Bastos (1994), a origem da palavra comprometimento advém do termo inglês commitmment, que tem significados pautados em quatro eixos: confiar, designar, desempenhar e envolver. Nos estudos sobre o comprometimento organizacional, observa-se a presença de diversos entendimentos e definições, o que torna complexa a tarefa de conceituar e fundamentar teoricamente o tema, muito embora haja consenso de que o conceito de comprometimento organizacional é multidimensional (ROMAN et al., 2012). Mowday, Porter e Steers (1979) definem 
comprometimento organizacional como a relação forte entre um indivíduo identificado com e envolvido em uma organização, que pode ser caracterizado por pelo menos três fatores: estar disposto a exercer esforço considerável em benefício da organização; forte crença e aceitação dos objetivos e valores da organização; forte desejo de se manter membro da organização. Roman et al. (2012, p. 7) destacam que diversos autores definem comprometimento organizacional como "[...] o desejo de permanecer como membro da organização; o orgulho por pertencer a uma organização; a identificação com objetivos, metas e valores da organização; o engajamento, o esforço, o empenho exercido em favor da organização."

O comprometimento organizacional afetivo (COA) tem sido entendido como a forte crença e a aceitação dos valores e objetivos da organização, isto é, um forte desejo de manter-se vinculado à organização esforçando-se em favor dela (CHANG JUNIOR, 2002). Zanelli, Borges-Andrade e Bastos (2004, p. 318) definem o COA como "[...] um estado no qual um indivíduo se identifica com uma organização particular e com seus objetivos, desejando manter-se afiliado a ela com vistas a realizar tais objetivos."

Neste estudo, os estilos de liderança serão medidos por meio da Escala Avaliação Estilo Gerenciais (EAEG), criada e validada por Melo (2004). A medida permite avaliar os estilos de liderança nas dimensões: Tarefa, Relacionamento e Situacional, na visão dos liderados. O COA será medido pela Escala de Comportamento Organizacional Afetivo (ECOA) criada e validada por Siqueira (2008). Trata-se de uma medida unidimensional, que permite avaliar a intensidade com que um empregado nutre sentimentos positivos frente à organização que o emprega.

Com base na relação entre os três estilos de liderança e o comprometimento organizacional afetivo, três hipóteses norteiam este estudo (Diagrama 1): H1: O Fator Tarefa não tem relação significativa com o comprometimento organizacional afetivo; H2: O Fator Relacionamento tem relação significativa e positiva com o comprometimento organizacional afetivo; H3: O Fator Situação tem relação significativa e positiva com o comprometimento organizacional afetivo. 
Diagrama 1 - Modelo teórico da pesquisa

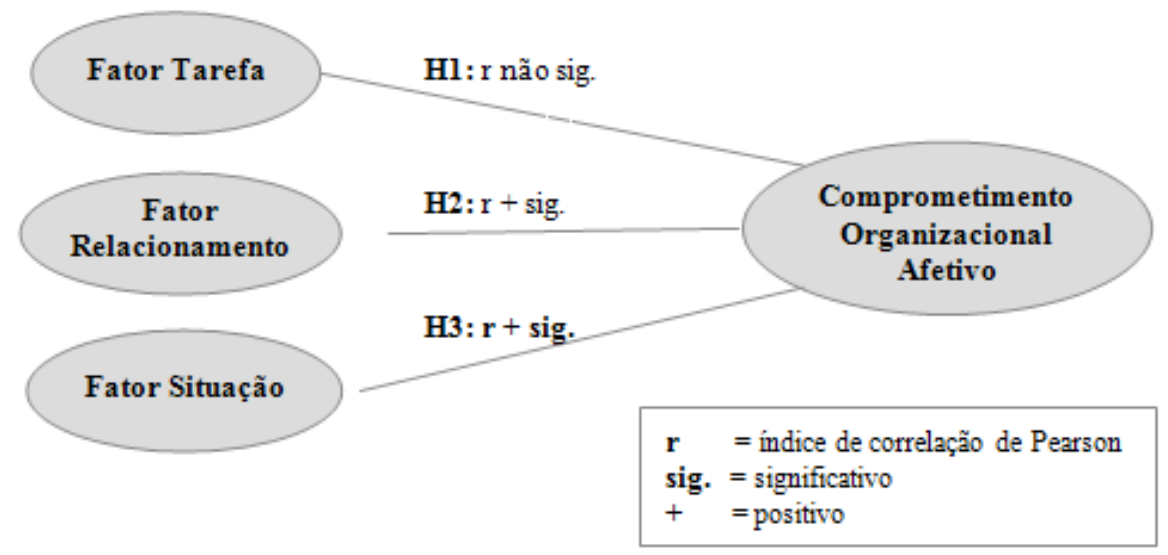

Fonte: os autores.

O modelo teórico adotado neste estudo se encontra sintetizado a seguir (Quadro 2) e detalhado em seção específica.

Este estudo encontra-se organizado a partir da seção introdutória, ora apresentada, seguida da fundamentação teórica acerca dos dois construtos que embasam este estudo, a saber, estilos de liderança e comprometimento organizacional afetivo, além de informações sobre estudos recentes. Na terceira seção há o detalhamento do método empregado na pesquisa. Na quarta seção é feita a apresentação dos resultados da pesquisa de campo, seguida pelas considerações finais.

Quadro 2 - Modelo teórico adotado na pesquisa

\begin{tabular}{|l|l|}
\hline $\begin{array}{l}\text { REFEREN- } \\
\text { CIAL TEÓRI- }\end{array}$ & $\begin{array}{l}\text { Construtos: Estilos de Liderança e Comprometimento Organizacional } \\
\text { Afetivo (COA) }\end{array}$ \\
\hline $\begin{array}{l}\text { PROBLEMA } \\
\text { DA PESQUISA }\end{array}$ & $\begin{array}{l}\text { Na atualidade, as organizações se desenvolvem em um contexto } \\
\text { altamente competitivo, o que remete à necessidade dos colaboradores } \\
\text { co se identificarem com a organização em que trabalham, assim como } \\
\text { o desafio de fortalecer o comprometime organizacional tem nas mãos, portanto, } \\
\text { uma vez que tal comprometimento é considerado fundamental para o } \\
\text { desempenho eficiente da organização. }\end{array}$ \\
\hline $\begin{array}{l}\text { QUESTÃO DE } \\
\text { ESTUDO }\end{array}$ & $\begin{array}{l}\text { O estilo do líder tem relação com o comprometimento afetivo dos } \\
\text { liderados com a organização? }\end{array}$ \\
\hline
\end{tabular}




\begin{tabular}{|c|c|c|c|c|c|c|c|}
\hline \multirow[b]{2}{*}{ OBJETIVOS } & \multicolumn{3}{|l|}{ Geral } & \multicolumn{2}{|c|}{$1^{\circ}$ Específico } & \multicolumn{2}{|c|}{$2^{\circ}$ Específico } \\
\hline & \multicolumn{3}{|c|}{$\begin{array}{l}\text { Analisar a relação entre } \\
\text { os estilos de liderança } \\
\text { e o comprometimento } \\
\text { organizacional afetivo } \\
\text { em trabalhadores de } \\
\text { uma empresa privada } \\
\text { em São Paulo. }\end{array}$} & \multicolumn{2}{|c|}{$\begin{array}{l}\text { Levantar os estilos de } \\
\text { liderança percebidos } \\
\text { pelos trabalhadores da } \\
\text { organização em rela- } \\
\text { ção aos seus superiores } \\
\text { imediatos. }\end{array}$} & \multicolumn{2}{|c|}{$\begin{array}{l}\text { Analisar se cada } \\
\text { um dos três estilos } \\
\text { de liderança dos } \\
\text { superiores imediatos } \\
\text { têm relação com o } \\
\text { comprometimento } \\
\text { organizacional afeti- } \\
\text { vo dos liderados. }\end{array}$} \\
\hline & \multicolumn{3}{|c|}{$1^{\mathrm{a}}$ Hipótese $(\mathrm{H} 1)$} & \multicolumn{2}{|c|}{$2^{\mathrm{a}}$ Hipótese $(\mathrm{H} 2)$} & \multicolumn{2}{|c|}{$3^{\text {a }}$ Hipótese (H3) } \\
\hline $\begin{array}{l}\text { HIPÓTESES } \\
\text { INVESTIGA- } \\
\text { DAS }\end{array}$ & \multicolumn{3}{|c|}{$\begin{array}{l}\text { O Fator Tarefa não } \\
\text { tem relação significati- } \\
\text { va com o comprometi- } \\
\text { mento organizacional } \\
\text { afetivo. }\end{array}$} & \multicolumn{2}{|c|}{$\begin{array}{l}\text { O Fator Relaciona- } \\
\text { mento tem relação } \\
\text { significativa e positiva } \\
\text { com o comprometi- } \\
\text { mento organizacional } \\
\text { afetivo. }\end{array}$} & \multicolumn{2}{|c|}{$\begin{array}{l}\text { O Fator Situação } \\
\text { tem relação signifi- } \\
\text { cativa e positiva com } \\
\text { o comprometimen- } \\
\text { to organizacional } \\
\text { afetivo. }\end{array}$} \\
\hline \multirow{4}{*}{$\begin{array}{l}\text { METODOLO- } \\
\text { GIA }\end{array}$} & \multicolumn{4}{|c|}{ Métodos empregados } & \multirow[b]{2}{*}{$\begin{array}{l}\text { Empresa } \\
\text { investigada }\end{array}$} & \multirow{2}{*}{$\begin{array}{l}\text { Instru- } \\
\text { mento de } \\
\text { coleta de } \\
\text { dados }\end{array}$} & \multirow{2}{*}{$\begin{array}{l}\text { Com- } \\
\text { posição } \\
\text { da } \\
\text { amostra }\end{array}$} \\
\hline & $\begin{array}{l}\text { Abor- } \\
\text { dagem }\end{array}$ & $\begin{array}{l}\text { Ob- } \\
\text { jetivo }\end{array}$ & $\begin{array}{l}\text { Proced } \\
\text { tos téc }\end{array}$ & $\begin{array}{l}\text { imen- } \\
\text { iicos }\end{array}$ & & & \\
\hline & \multirow{2}{*}{$\begin{array}{l}\text { Quan- } \\
\text { titativa }\end{array}$} & \multirow{2}{*}{$\begin{array}{l}\text { Des- } \\
\text { criti- } \\
\text { vo }\end{array}$} & $\begin{array}{l}\text { Pesqui } \\
\text { campo }\end{array}$ & & \multirow{2}{*}{$\begin{array}{l}\text { Prestadora } \\
\text { paulista de ser- } \\
\text { viços na área } \\
\text { de alimentação }\end{array}$} & \multirow{2}{*}{$\begin{array}{l}\text { Questio- } \\
\text { nário }\end{array}$} & \multirow{2}{*}{$\begin{array}{l}92 \text { tra- } \\
\text { balha- } \\
\text { dores }\end{array}$} \\
\hline & & & $\begin{array}{l}\text { Pesqui } \\
\text { levanta }\end{array}$ & $\begin{array}{l}\text { a de } \\
\text { mento }\end{array}$ & & & \\
\hline
\end{tabular}

Fonte: os autores.

\section{FUNDAMENTAÇÃO TEÓRICA}

No final da década de 1940, após a Segunda Guerra Mundial, o Institute for Social Research iniciou um programa de pesquisas em grande escala empregando novas metodologias para estudar os complexos problemas humanos da administração (FERNANDES, 2012). O objetivo era identificar as características do comportamento do líder e sua relação com a eficácia da liderança. Desses estudos, duas dimensões comportamentais do líder surgiram como resultado: a centrada no empregado e a centrada no serviço.

Segundo Longaray e Giesta (1999), Kurt Lewin, na década de 1930, havia orientado seus alunos Rauph White e Ronald Lippitt em uma pesquisa que envolvia três grupos de crianças submetidas a diferentes lideranças. Como fruto desse estudo surgiu a teoria que se tornou conhecida como a teoria dos três estilos de White e Lippitt (1960 apud LONGARAY; GIESTA, 1999), que introduziu uma nova perspectiva na abordagem dos estilos de liderança, classificando-os em Autocrático 
(centralizador), Democrático (participativo) e Liberal (descentralizador). As diferenças entre os estilos de liderança se posicionam no plano da participação dos empregados nas decisões. Os estilos de liderança apresentados forneceram uma chave essencial para os estudos posteriores sobre liderança (PANTOJA, 2005). Segundo Uris (1967), há uma relação entre os estilos de liderança e as atividades dos empregados. Assim, eles tendem a cooperar no estilo democrata, a obedecer no estilo autocrata e a serem eficientes no estilo liberal.

As teorias X e Y de McGregor (1973) promoveram uma aproximação das Ciências Humanas à Administração. Segundo Fraga (2005, p. 11), aquele autor passou mais de vinte anos estudando as organizações com o objetivo de responder à questão: "Os dirigentes verdadeiramente eficientes são natos ou fazem-se por si??" Assim, em termos de Tarefa da Administração, ele considerou que o pensamento predominante na época era de pessoas passivas e desinteressadas. McGregor (1973) atribui a esse modelo o nome de Teoria X. Apoiado nas elaborações de Maslow, ele considerou que a melhor maneira de demonstrar a inadequação dessas proposições seria por meio da análise da motivação. Portanto, a partir das necessidades inerentes ao ser humano ele desenvolveu um novo modelo de gestão de produtividade humana (participativa) conhecido como Teoria Y. Para McGregor (1980), a discussão da Teoria $\mathrm{X}$ e da Teoria Y poderia causar a impressão de que líderes que aceitam os pressupostos da Teoria $\mathrm{X}$ sobre a natureza geralmente direcionam, controlam e supervisionam estritamente os funcionários, enquanto os líderes da Teoria Y procuram apoiar e facilitar as coisas para os seus funcionários, e que tal conclusão pode ser equivocada. De acordo com o autor, pelo menos quatro variáveis implicariam a definição do estilo de liderança: características do líder; atitudes, necessidades e características dos seguidores; finalidade, estrutura, natureza das tarefas e outras características da organização; e, o meio social, econômico e político. Conclui-se que a liderança não é propriedade do indivíduo, mas sim, uma relação complexa entre essas variáveis.

A perspectiva da Grade de Liderança foi desenvolvida por Robert Blake e Jane Mouton, em 1964. Essa perspectiva mede a preocupação de um gerente com as pessoas e com a produção (BLAKE; MOUTON, 1975). Verifica-se que o eixo horizontal dispõe os resultados relativos ao interesse pela produção em uma escala de valor que varia entre um e nove, enquanto o eixo vertical dispõe o interesse pelas pessoas em uma mesma escala de valoração. Segundo Schermerhorn Junior, Hunt e Osborn (2005), o Estilo Gerencial de Equipe é o ideal, uma vez que corresponde ao alto nível nas duas dimensões. Burns (1978) apresentou dois modelos distintos de liderança: a transformacional e a transacional. Na liderança transformacional o líder 
estimula o desenvolvimento das necessidades de autorrealização e comprometimento conforme os valores e interesses grupais. O líder transformacional leva suas equipes a ultrapassarem os seus interesses próprios para o coletivo. A liderança transacional foi definida como a capacidade do líder de atender aos interesses de cada membro da sua equipe. Assim, nesse modelo, não há preocupação com o coletivo, mas uma lógica de recompensa e punição ou até mesmo uma negociação entre os interesses individuais.

Paul Hersey e Kennedy Blanchard são os elaboradores da teoria de liderança situacional. Trata-se de um modelo situacional de análise da liderança com ênfase nos liderados e que introduziu uma variável muito importante: a maturidade dos subordinados. Segundo Hersey e Blanchard (1986), a eficácia da liderança depende da adequação do estilo de liderança ao grau de maturidade dos subordinados. Maturidade deve ser entendida como a capacidade e a vontade das pessoas de assumirem a responsabilidade pela orientação do seu próprio comportamento e que se divide em dois componentes: a maturidade no trabalho e a maturidade psicológica. De acordo com os autores, mediante esse crivo de maturidade dos subordinados, é possível definir quatro estilos específicos de liderança: Dirigir, Persuadir/Vender/ Treinar (coaching), Participar e Delegar. Para eles, qualquer estilo de liderança é eficaz, desde que esteja adequado à maturidade dos subordinados.

Para Stefano e Gomes Filho (2003), a abordagem situacional passa a visualizar como realmente a liderança flui, deixando de lado os comportamentos dos líderes, fazendo surgir, dessa forma, a figura dos empregados e seus anseios em relação ao estilo de liderança adotado. Essa abordagem se torna atraente por considerar alguns critérios que as abordagens anteriores não revelavam, como, por exemplo, a figura do líder, os empregados e a situação; isso a torna útil para a compreensão de determinadas situações.

Do ponto de vista teórico e empírico, o termo inteligência emocional foi utilizado pela primeira vez por Mayer, DiPaolo e Salovey (1990). Contudo, foi Goleman (2002) quem apresentou o conceito de inteligência emocional sobre a perspectiva nos estilos de liderança. Os resultados de suas pesquisas sugerem que a inteligência emocional está relacionada ao monitoramento dos sentimentos em si e nos outros, na discriminação entre ambos e na utilização dessa informação para guiar o pensamento e as ações. Os estilos de liderança propostos por Goleman (2002) surgiram de diferentes componentes da inteligência: coercitivo, autoritário, paternalista, democrático, pressionador e conselheiro.

A busca de relações favoráveis no trabalho em equipe vem sendo motivo de pesquisas e publicações de autores como Louis Spain e Paul Worthing, que 
sugerem um dos grandes desafios para o progresso da sociedade contemporânea: conseguir alcançar o consenso na diversidade (MAGALHÃES, 2001). Quando as lideranças estabelecem vínculos seguros, propiciam o desenvolvimento de relações de confiança, definidas por Goleman (2002) como "Ressonância”, que propicia lidar com as adversidades por meio da inteligência emocional na busca por melhores desempenhos. Já o vínculo ansioso é marcado por incertezas, desconfianças que, então, é a liderança chamada de "Dissonância". De forma geral, entende-se como fator desencorajador, desanimando e afugentando a equipe.

Os estudos referentes aos estilos de liderança mencionam o líder coach. O coaching é definido como uma ferramenta gerencial que se utiliza de técnicas não diretivas para estimular o executivo a refletir sobre o seu comportamento e suas decisões visando à escolha da melhor opção e se pautando na otimização e no desenvolvimento da carreira e aperfeiçoamento pessoal (DI STEFANO, 2012; ARAUJO, 2011; GASPAR; PORTÁSIO, 2009).

O coaching é uma filosofia de liderança que acredita no pressuposto de que a aquisição e o desenvolvimento são processos ininterruptos e de responsabilidade de todos, e não somente de acontecimentos isolados e restritos no tempo e estimulados pelas chefias (GASPAR; PORTÁSIO, 2009). Blanco (2006) esclarece que o coaching não deve ser confundido com práticas como aconselhamento ou consultoria, uma vez que não é papel do coach responder e/ou ensinar alguém como fazer algo, tampouco o coaching deve ser confundido com a prática conhecida como mentoring (mentoria), o que, segundo a autora, é bastante frequente. O coaching, além de estimular a criatividade, encoraja as pessoas a serem mais flexíveis e adaptáveis nos seus estilos de liderança. Observa-se que importantes temas debatidos atualmente pelos estudiosos organizacionais estão implícitos nesse elenco de competências: ética, relacionamentos interpessoais, comunicação, cognição e planejamento.

Em relação ao comprometimento organizacional em seus aspectos conceituais e teóricos, Medeiros et al. (2003) destacam que, na década de 1990, três enfoques predominaram no estudo do comprometimento organizacional: afetivo, instrumental/calculativo e normativo. Segundo os autores, tais enfoques foram tratados isoladamente em algumas pesquisas, como é o caso do enfoque afetivo, ou em modelos multidimensionais, como é o caso do modelo de conceitualização de três componentes do comprometimento organizacional proposto pelos pesquisadores Meyer e Allen (1991).

O enfoque afetivo dominou por um tempo a literatura do comprometimento organizacional. Segundo Medeiros et al. (2003), os estudos foram liderados por 
Lyman Porter (MOWDAY; PORTER; STEERS, 1979, 1982) e tiveram início na década de 1970. Mesmo reconhecendo a existência de uma corrente comportamental para definir o comprometimento, os pesquisadores tratavam a questão em uma perspectiva atitudinal. Para esses estudiosos, o comprometimento vai muito além de uma postura de lealdade passiva com a organização e envolve um relacionamento ativo, que busque o seu bem-estar.

Meyer e Allen (1991) conceituam o comprometimento organizacional em três componentes: comprometimento como um apego à organização (affective commitment), ou afetivo; comprometimento percebido como custos associados a deixar a organização, chamado pelos autores de continuance commitment e reconhecido no Brasil como instrumental; e, comprometimento como uma obrigação de permanecer na organização, chamado inicialmente pelos autores de obligation e depois de normative commitment, e no Brasil de normativo.

Segundo Allen e Meyer (1990, p. 3), três dimensões caracterizam os indivíduos: empregados com forte comprometimento afetivo permanecem na organização porque eles querem; empregados com comprometimento instrumental permanecem na organização porque precisam; empregados com comprometimento normativo permanecem porque sentem que são obrigados.

Siqueira, Costa e Filenga (2012) testaram um modelo teórico no qual duas vertentes de percepção de justiça (distributiva e de procedimentos) eram antecedentes de percepção de suporte e este de comprometimento afetivo. A amostra analisada é composta por 1.295 funcionários do setor público. Os autores observaram que o desempenho é maior quando as pessoas são comprometidas afetivamente com suas organizações. O comprometimento organizacional afetivo tem sido objeto de estudo na academia com outras variáveis como: justiça no trabalho, percepção do suporte organizacional, desenvolvimento de carreira que demonstram a importância dos profissionais com o comprometimento organizacional afetivo para a melhoria do desempenho das organizações (RIOS, 2011; ROMAN et al., 2012; ROSENSTOCK, 2011); assim como estudos sobre liderança também fortalecem a teoria sobre o tema (CAVICCHIOLI, 2008; BENEVIDES, 2010; GONÇALVES, 2008; SILVA, 2009; SANTOS, 2010; ROCHA; CAVALCANTE; SOUZA, 2011; ARAUJO, 2011; ROVEDA, 2010), principalmente com as características do gestor brasileiro. 


\section{MÉTODO}

Este estudo se vale da abordagem quantitativa (RICHARDSON, 1999; POLIT; BECK; HUNGLER, 2004), orientado, essencialmente, pelos conceitos de estilo de liderança e comprometimento organizacional afetivo e partiu do pressuposto de que os líderes funcionam como guias emocionais das equipes de trabalho. Por meio de procedimentos estruturados e um de instrumento formal - devidamente detalhados mais adiante - foram coletados dados que receberam inicialmente um tratamento estatístico e, posteriormente, um tratamento analítico. Em relação ao objetivo, este estudo se caracteriza como descritivo (GIL, 1999; RAUPP; BEUREN, 2006; ANDRADE, 2002), pois analisa a relação entre os estilos de liderança e o comprometimento organizacional afetivo em trabalhadores de uma determinada empresa. Caracteriza-se, ainda, como uma pesquisa de campo delineada por uma pesquisa de levantamento (GIL, 1999) realizada com os trabalhadores de uma empresa privada.

A definição dos participantes para compor a amostra foi realizada por conveniência em uma empresa prestadora de serviços na área de alimentação estabelecida no município de São Paulo. Para a quantidade de participantes, seguiu-se o critério estabelecido por Tabachnick e Fidell (2001, p. 123), visando compor a amostra mínima, cujo cálculo realizado considerou o número de variáveis independentes por meio da fórmula: $\mathrm{n} \geq 50+8 \mathrm{x}$ (números de variáveis independentes). Considerando-se como variáveis independentes os três estilos de liderança (Tarefa, Relacionamento, Situacional), esse número mínimo seria de 74. A amostra contém 92 participantes, revelando-se, portanto, satisfatória.

A coleta de dados foi realizada em uma empresa nacional, fundada em 1971 por um grupo de executivos, sob uma visão inovadora da prestação de serviços na área de alimentação. Nos primeiros anos, a empresa estava sediada no bairro de Higienópolis, próximo ao centro da cidade e tinha como principal foco o transporte de refeições prontas produzidas na própria sede. No decorrer dos anos 1980, a empresa ampliou suas atividades para servir refeições produzidas internamente nos restaurantes das empresas. Atualmente, a sede da empresa está localizada no bairro do Sumaré e, segundo seus diretores, está entre as mais destacadas no setor de alimentação; conta com uma equipe de 500 funcionários e presta serviço de alimentação nos mais diversos segmentos do mercado. Sua área de atuação abrange todo o Estado de São Paulo e Minas Gerais.

A coleta de dados foi realizada por meio de contato direto (RICHARDSON, 1999) com os participantes que aderiram à pesquisa com a assinatura do Termo de 
Consentimento Livre e Esclarecido (TCLE). Inicialmente, após conhecimento e admissão do projeto de pesquisa pela diretoria e gerências da empresa, os participantes foram convidados para um único encontro no qual receberam o modelo. $\mathrm{Na}$ ocasião, foram apresentados os objetivos da investigação e feitos os esclarecimentos de dúvidas, estabelecendo-se, assim, um processo de consentimento. A aplicação ocorreu nas instalações da empresa, que disponibilizou uma sala na qual havia mesa, cadeiras, ar condicionado, boa iluminação, boa vedação acústica, resguardando o conforto e a privacidade dos participantes. Como o aproveitamento foi de 40 questionários válidos, o processo de coleta de dados foi repetido mais duas vezes, com funcionários de outras unidades, alcançando 92 questionários válidos. O processo todo foi realizado em agosto, novembro e dezembro de 2013.

O instrumento utilizado para a coleta de dados foi o questionário autopreenchível, elaborado apenas com perguntas fechadas e composto por duas escalas e dados demográficos, conforme a seguir:

a) Escala de Avaliação do Estilo Gerencial (EAEG) - Essa Escala permite ao trabalhador descrever 19 componentes de suas chefias por meio de uma escala de cinco pontos ( 1 = nunca age assim, $2=$ raramente age assim, 3 = ocasionalmente age assim, $4=$ frequentemente age assim e 5 = sempre age assim), construída por Melo (2004), tendo como índice de precisão um valor de 0,94 para o fator relacionamento (exemplo: encontra tempo para ouvir os membros do grupo); 0,72 para o fator tarefa (exemplo: valoriza a disciplina e a subordinação); e, 0,83 para o fator situacional (exemplo: dá liberdade de trabalho aos subordinados que se mostram seguros diante da tarefa a ser executada).

b) Escala de Comprometimento Organizacional Afetivo (ECOA) - Trata-se de uma medida unidimensional que permite avaliar a intensidade com que um empregado nutre sentimentos positivos e negativos frente à organização que o emprega. A escala foi construída e validada por Siqueira (2008), composta por 18 itens, apresentando valores de correlação item-total entre 0,50 e 0,83 . A precisão da escala ( $\alpha$ de Cronbach) foi de 0,95. A autora selecionou os itens com maior correlação item-total e criou uma versão reduzida com cinco itens e confiabilidade igual a 0,93 (exemplo: orgulhoso(a) dela), já considerado satisfatório para a investigação científica. O respondente determina em 
uma escala de cinco pontos $(1=$ Nada, $2=$ Pouco, $3=$ Mais ou menos, $4=$ Muito e $5=$ Extremamente).

c) Dados demográficos dos participantes - Ao final do questionário estão levantados os dados de caracterização dos participantes (idade, gênero, estado civil, tempo de serviço na empresa) e os dados funcionais (se ocupam cargos de chefia, tempo de trabalho na empresa).

Todos os respondentes foram orientados sobre a proposta do trabalho e a natureza acadêmica deste estudo. Foi solicitada aos respondentes a assinatura TCLE garantindo que as informações prestadas nos instrumentos fossem utilizadas para fins acadêmicos e mantidas sob total sigilo. Ressalta-se que não houve qualquer tipo de símbolos, marcas ou números que possibilitassem, no futuro, identificar o participante e os instrumentos por eles preenchidos. O respondente da pesquisa pôde desistir de sua participação a qualquer momento, o que não acarretaria qualquer tipo de penalização - estando totalmente livre para continuar ou encerrar a sua participação. Contudo, todos os colaboradores convidados a participar da pesquisa aceitaram os termos e não houve desistência.

\section{APRESENTAÇÃO DOS RESULTADOS}

Os dados coletados, todos representados por indicadores numéricos, formaram um banco de dados para o tratamento no software estatístico Statistical Package for the Social Sciences (SPSS), versão 19.0. Foi realizada, a priori, uma análise exploratória dos dados para verificar a precisão de entrada de dados, outliers e respostas omissas. Depois da exploração, análises descritivas foram realizadas com a finalidade de caracterizar os participantes, assim como as correlações entre as variáveis ( $\mathrm{r}$ de Pearson). Também foram calculados os alfas de Cronbach para as escalas utilizadas.

A análise do perfil dos entrevistados revelou a caracterização da amostra na Tabela 1. 
Tabela 1 - Perfil sociodemográfico dos participantes $(\mathrm{N}=92)$

\begin{tabular}{|c|c|c|c|}
\hline Características & & Frequência & $\%$ \\
\hline \multirow{3}{*}{ Gênero } & Feminino & 76 & 82,6 \\
\hline & Masculino & 16 & 17,4 \\
\hline & Solteiro & 52 & 56,5 \\
\hline \multirow[t]{4}{*}{ Estado civil } & Casado & 31 & 33,7 \\
\hline & Outros & 9 & 9,8 \\
\hline & Menor de 20 anos & 3 & 3,3 \\
\hline & $20-30$ anos & 35 & 38 \\
\hline \multirow[t]{6}{*}{ Idade } & $31-40$ anos & 33 & 35,9 \\
\hline & $41-50$ anos & 16 & 17,4 \\
\hline & $51-60$ anos & 5 & 5,4 \\
\hline & Ensino Fundamental & 2 & 2,2 \\
\hline & Ensino Médio & 32 & 34,8 \\
\hline & Ensino Superior & 41 & 44,6 \\
\hline \multirow[t]{3}{*}{ Escolaridade } & Especialização & 17 & 18,5 \\
\hline & Mestrado & 0 & 0 \\
\hline & Doutorado & 0 & 0 \\
\hline \multirow{2}{*}{ Cargo de liderança } & Sim & 49 & 53,3 \\
\hline & Não & 43 & 46,7 \\
\hline \multirow{6}{*}{ Tempo de empresa } & Menos de 6 meses & 14 & 17,9 \\
\hline & De 6 meses a 1 ano & 15 & 19,2 \\
\hline & De 1 a 5 anos & 38 & 48,7 \\
\hline & De 6 a 10 anos & 16 & 20,5 \\
\hline & 11 a 20 anos & 8 & 10,3 \\
\hline & Acima de 20 anos & 1 & 1,3 \\
\hline
\end{tabular}

Fonte: os autores.

Os participantes da pesquisa $(\mathrm{n}=92)$ eram predominantemente do gênero feminino $(76=82,6 \%)$ e solteiros $(52=56,5 \%)$ entre 20 e 40 anos $(68=73,9 \%)$. A maioria possui Ensino Superior $(41=44,6 \%)$, seguindo pelos que possuem Nível Médio $(32=34,8 \%)$, alguns têm Especialização $(17=18,5 \%)$ e dois $(2,2 \%)$ têm Ensino Fundamental. Nenhum funcionário tem mestrado ou doutorado. Quanto ao tempo de empresa, a distribuição segue próxima a uma curva normal, com concentração de um a cinco anos $(38=48,7 \%)$, variando entre menos de seis meses a 25 anos de empresa. 
A média de idade é 33 anos (desvio padrão $=9,4$ e coeficiente de variação $=$ $0,28)$, o que representa uma boa concentração em torno dessa idade. Já o tempo de empresa médio ficou em 4,5 anos (desvio padrão $=4,49$ e coeficiente de variação $=$ 1,03); porém, esse número não representa a amostra, já que o coeficiente de variação é bem alto (muito maior que 0,3 ). Vale ressaltar que mais da metade dos pesquisados $(49=53,3 \%)$ possui cargo de liderança e respondeu às escalas em relação a seus chefes.

$\mathrm{Na}$ análise das características pessoais, observa-se que a predominância é feminina. Mowday, Porter e Steers (1982) destacam que as mulheres tendem a ser mais comprometidas do que os homens. Mathieeu e Zajac (1990 apud MEDEIROS et al., 2003) consideram que a idade é um dos fatores que se relacionam com o comprometimento organizacional. Meyer e Allen (1991) sugerem que os trabalhadores mais velhos são mais comprometidos atitudinalmente na organização como, por exemplo, de forma afetiva, pelo fato de estarem mais satisfeitos com as suas atividades, ocupando melhores cargos, o que os leva a justificar a sua permanência na organização. Os trabalhadores mais velhos tendem a ter uma posição organizacional mais elevada ocupando cargos superiores em relação aos mais novos, confirmando o nível de comprometimento instrumental, mais relacionado com as perdas financeiras ao deixarem a organização.

\section{ANÁLISE DOS RESULTADOS}

Foram calculados os índices de precisão das escalas (Alfa de Cronbach), cujos resultados são apresentados na Tabela 2:

Tabela 2 - Índice de precisão das escalas no trabalho de campo

\begin{tabular}{llll}
\hline Escala & Fator & Quantidade de itens & Alfa de Cronbach \\
\hline Estilo de liderança & Estilo Tarefa & 6 & 0,69 \\
& $\begin{array}{l}\text { Estilo Relacionamento } \\
\text { Estilo Situacional }\end{array}$ & 9 & 0,9 \\
$\begin{array}{l}\text { Comprometimento } \\
\begin{array}{l}\text { Organizacional } \\
\text { afetivo }\end{array}\end{array}$ & --- & 5 & 0,71 \\
\hline Fonte: & 4 & 0,93 \\
\hline
\end{tabular}

Fonte: os autores.

Os índices de precisão medidos pelo Alfa de Cronbach demonstram que existe convergência entre os itens das escalas, pois seus valores ficaram acima de 
0,69, considerados aceitáveis para pesquisas nas Ciências Sociais (HAIR JUNIOR. et al., 2005) (Tabela 3):

Tabela 3 - Análises gerais das variáveis no grupo pesquisado

\begin{tabular}{llll}
\hline Variáveis & Média & Desvio padrão & CV \\
\hline COA & 3,4 & 0,82 & 0,24 \\
Estilo Relacionamento & 3,9 & 0,91 & 0,23 \\
Estilo Tarefa & 4 & 0,57 & 0,14 \\
Estilo Situacional & 4 & 0,62 & 0,16 \\
\hline
\end{tabular}

Fonte: os autores.

Foi encontrado no estilo Relacionamento a média 3,9 (desvio padrão 0,91) e coeficiente de variação 0,23 . No estilo Tarefa a média de 4,0 (desvio padrão 0,57 ) e coeficiente de variação 0,14. No estilo Situacional a média de 4,0 (desvio padrão 0,62 ) e o coeficiente de variação 0,16 . A média alta representa que existe um forte estilo de liderança Tarefa e Situacional; embora o estilo de liderança Relacionamento também tenha uma média alta, não é tão representativo do grupo como os estilos de liderança Tarefa e Situacional, em razão do coeficiente de variação acima de $20 \%$. Conforme análise das respostas dos pesquisados, concluiu-se que a média 3,4 (desvio padrão $=0,82$ ) está um acima do meio da escala.

O coeficiente de variação pode ser definido como medida de dispersão relativa empregada para estimar a precisão de experimentos e representa o desvio padrão expresso como porcentagem da média. Sua principal qualidade é a capacidade de comparação de distribuições diferentes. Na pesquisa foi encontrado um coeficiente de variação de 0,24 , o que representa uma moderada dispersão em torno dessa média.

Para a análise qualitativa do comprometimento, foi feita uma classificação dos liderados em decorrência da pontuação do COA, seguindo os critérios de pontuação: 1 a 2,33: não comprometidos; 2,34 a 3,66: indefinidos; e 3,67 a 5: comprometidos. A classificação permitiu distribuir os liderados por frequência. A pesquisa demonstra que $42 \%$ dos empregados dessa empresa se sentem orgulhosos, contentes, entusiasmados, interessados, animados e comprometidos afetivamente com a empresa. Apenas $8 \%$ demonstram explicitamente que não estão comprometidos afetivamente com a organização pesquisada. $O$ interessante é se encontrar o número de $50 \%$ de empregados com comprometimento indefinido, algo que não se consegue detectar o motivo. 
A seguir, encontram-se apresentados os resultados obtidos para a correlação entre idade, tempo de empresa e score de comprometimento (Tabela 4):

Tabela 4 - Correlação entre idade, tempo de empresa e score de comprometimento

\begin{tabular}{lllll}
\hline Itens & & Idade & Tempo na empresa & COA \\
\hline \multirow{3}{*}{ Idade } & Pearson Correlation & 1 &, $474^{\star \star}$ &, $223^{\star}$ \\
& Sig. (2-tailed) & & 0 & 0,032 \\
& $\mathrm{~N}$ & 92 & 92 & 92 \\
Tempo na & Pearson Correlation &, $474^{\star \star}$ & 1 & 0,08 \\
empresa & Sig. (2-tailed) & 0 & & 0,451 \\
& $\mathrm{~N}$ & 92 & 92 & 92 \\
& Pearson Correlation &, $223^{\star}$ & 0,08 & 1 \\
COAm & Sig. (2-tailed) & 0,032 & 0,451 & \\
& $\mathrm{~N}$ & 92 & 92 & 92 \\
\hline
\end{tabular}

Fonte: os autores.

Notas:

${ }^{\star}$ Correlation is significant at the 0.05 level (2-tailed).

${ }^{\star}$ Correlation is significant at the 0.01 level (2-tailed).

Segundo Costa e Bastos (2009), alguns perfis tendem a estar associados com o comprometimento, como pessoas casadas, idade e tempo na organização. Ficou confirmada na pesquisa que a idade tem fraca correlação com o comprometimento das pessoas $(\mathrm{r}=0,223)$, porém significativa $(\mathrm{p}<0,05)$. No entanto, o tempo na empresa não teve essa correlação significativa.

A seguir, são apresentados os resultados da análise de correlação entre o comprometimento afetivo e os estilos de liderança (Tabela 5):

Tabela 5 - Correlação entre comprometimento organizacional afetivo e estilos de liderança (relacionamento, tarefa e situacional) (continua)

\begin{tabular}{llllll}
\hline Itens & & COAm & RelacM & TarefM & Situacm \\
\hline \multirow{4}{*}{ COAm } & Pearson Correlation & 1 &, 204 &, $243^{\star}$ &, $209^{\star}$ \\
& Sig. (2-tailed) & &, 051 &, 020 &, 045 \\
& $\mathrm{~N}$ & 92 & 92 & 92 & 92 \\
& Pearson Correlation &, 204 & 1 &, $571^{\star \star}$ &, $500^{\star \star}$ \\
\multirow{2}{*}{ RelacM } & Sig. (2-tailed) &, 051 & &, 000 &, 000 \\
& $\mathrm{~N}$ & 92 & 92 & 92 & 92 \\
\hline
\end{tabular}


(conclusão)

\begin{tabular}{llllll}
\hline & Pearson Correlation &, $243^{\star}$ &, $571^{\star \star}$ & 1 &, $496^{\star \star}$ \\
TarefM & Sig. (2-tailed) &, 020 &, 000 & &, 000 \\
& N & 92 & 92 & 92 & 92 \\
& Pearson Correlation &, $209^{\star}$ &, $500^{\star \star}$ &, $496^{\star \star}$ & 1 \\
\multirow{2}{*}{ Situacm } & Sig. (2-tailed) &, 045 &, 000 &, 000 & \\
& $\mathrm{~N}$ & 92 & 92 & 92 & 92 \\
\hline
\end{tabular}

Fonte: os autores.

Notas:

${ }^{\star}$ Correlation is significant at the 0.05 level (2-tailed).

${ }^{\star \star}$ Correlation is significant at the 0.01 level (2-tailed).

O índice de correlação entre o estilo de liderança Relacionamento e o COA foi de 0,204, portanto, não significativo. A correlação entre o estilo de liderança Tarefa e o COA foi de 0,243 , baixa, porém significativa $(p<0,05)$. Entre o COA e o estilo de liderança Situacional, a correlação foi de 0,209, demonstrando também uma correlação baixa, porém significativa $(\mathrm{p}<0,05)$. Os três estilos de liderança têm correlação moderada entre si (entre 0,496 e 0,571), revelando que um líder é percebido pelo seu subordinado como não sendo de um estilo único exclusivamente, ou seja, as pessoas utilizam os três estilos, com pessoas diferentes ou em momentos diferentes.

$\mathrm{Na}$ análise qualitativa dos líderes, para se classificarem os estilos dos líderes dos pesquisados, foi adotado o critério de maior média no estilo (na precisão de uma casa decimal). Quando houve empate na maior pontuação em mais de um estilo, o líder foi classificado como indefinido. Foram encontrados no estilo Relacionamento a média 3,9 (desvio padrão 0,91) e o coeficiente de variação 0,23. No estilo Tarefa, a média de 4,0 (desvio padrão 0,57 ) e o coeficiente de variação 0,14 . No estilo Situacional, a média de 4,0 (desvio padrão 0,62 ) e o coeficiente de variação 0,16 . A média alta representa que existe um forte estilo de liderança Tarefa e Situacional; embora o estilo de liderança Relacionamento também tenha uma média alta, não é tão representativo como os estilos de liderança Tarefa e Situacional.

Há uma distribuição de todos os estilos na empresa, com uma percepção pelos liderados um pouco mais para o estilo Tarefa dos seus líderes. Vale destacar que 19\% das pessoas reconheceram pelo menos dois estilos mais fortes dos seus líderes. 
Tabela 6 - Teste de Bootstrap com 300 amostras entre os 92 participantes

\begin{tabular}{|c|c|c|c|c|c|c|c|c|c|}
\hline & & & & COAm & RelacM & TarefM & Situacm & Idade & $\begin{array}{l}\text { Tempo } \\
\text { na em- } \\
\text { presa }\end{array}$ \\
\hline \multirow[t]{7}{*}{ COAm } & \multicolumn{3}{|c|}{ Pearson Correlation } & 1 & ,204 & ,243 & ,209 & ,223 & ,080 \\
\hline & \multicolumn{3}{|c|}{ Sig. (2-tailed) } & &, 051 & ,020 &, 045 &, 032 & ,451 \\
\hline & \multicolumn{3}{|l|}{$\mathrm{N}$} & 92 & 92 & 92 & 92 & 92 & 92 \\
\hline & \multirow[t]{4}{*}{ Bootstrap } & Bias & & 0 & ,024 &,- 003 &, 005 &, 002 &,- 007 \\
\hline & & Std. Error & & 0 & ,137 & ,096 & ,087 & 074 & ,076 \\
\hline & & $\begin{array}{l}95 \% \text { Con- } \\
\text { fidence }\end{array}$ & Lower & 1 &,- 006 & ,061 &, 048 & ,091 &,- 101 \\
\hline & & Interval & Upper & 1 & ,491 & ,429 & ,383 & ,363 & ,215 \\
\hline
\end{tabular}

Fonte: os autores.

Foi realizado um teste de Bootstrap para avaliar se, em amostras menores, permanece a relação entre os estilos de liderança e o comprometimento afetivo. Nesse teste, foram feitas 300 amostras entre os 92 participantes, resultando variações muito grandes nas correlações com o COA. Por exemplo, a correlação entre o COA e o estilo Tarefa, que foi o mais alto dos três, variou nas amostras menores do mesmo grupo, entre 0,061 e 0,429 (terceira coluna e últimas duas linhas de números), de forma que não se pode afirmar que o estilo de liderança influencie o comprometimento organizacional afetivo. $\mathrm{O}$ erro padrão mais baixo foi maior que 0,07 (7\%), superior ao mínimo aceitável de 0,05 para ser considerado significativo (Tabela 6).

Os estilos de liderança, conforme demonstrado, não possuem relação com o comprometimento organizacional afetivo. Portanto, os estilos de liderança não são capazes de alterar nem de diminuir de forma significativa um aumento nos resultados esperados pela organização. Existem outras variáveis expostas na teoria que impactam a percepção dos empregados nos seus desempenhos e resultados.

Embora Stefano e Gomes Filho (2003) afirmem que os líderes têm a responsabilidade de dirigir as emoções dos liderados, o comprometimento organizacional afetivo não é desenvolvido por um processo emocional, mas por um processo cognitivo (SIQUEIRA, 2008) que a pessoa desenvolve comparando seus valores e objetivos com os da organização, desejando permanecer como membro e empenhandoesforçoem favordela (CHANGJUNIOR, 2002;ZANELLI; BORGESANDRADE; BASTOS, 2004). Dessa forma, parece que, independentemente do estilo de liderança adotado pelos líderes, o comprometimento do empregado com a 
organização acontecerá conforme suas percepções sobre a organização nas variáveis de justiça, comunicação, cultura, carreiras, políticas organizacionais claras voltadas para gerar o bem-estar profissional e pessoal do empregado, conforme as pesquisas apontadas por Siqueira, Costa e Filenga (2012), Rios (2011); Roman et al. (2012) e Rosenstock (2011).

\section{CONSIDERAÇÕES FINAIS}

Esta pesquisa teve como objetivo geral analisar a relação entre o estilo de liderança e o comprometimento organizacional afetivo. A amostra revelou a predominância de mulheres $(82,6 \%)$, solteiras (56,5\%), na faixa etária entre 20 e 40 anos (73,9\%), com Ensino Superior (44,6\%), exercendo cargos de liderança (53,3\%) e com tempo na empresa que varia entre um e cinco anos $(48,7 \%)$.

Em relação aos estilos de liderança, constatou-se que 26\% dos entrevistados percebem sua liderança voltada para a Situação, 22\% para os Relacionamentos, 33\% para a Tarefa e 19\% não se definiram; isto é, os resultados apontaram para mais de um estilo, não sendo possível, portanto, fazer nenhuma indicação. Em relação ao comprometimento organizacional afetivo, do total da amostra, apenas $8 \%$ dos entrevistados foram considerados descomprometidos, $42 \%$ comprometidos e $50 \%$ indefinidos (classificação: intervalo 2,34 a 3,66).

Para o cumprimento dos objetivos estabelecidos foram formuladas três hipóteses, das quais apenas uma foi validada. A primeira hipótese (H1 - O fator Tarefa não tem relação significativa com o comprometimento organizacional afetivo) não se confirmou, pois apesar de correlação fraca e variável em razão $\mathrm{da}$ amostra, os índices foram significativos $(\mathrm{r}=0,243$ e $\mathrm{p}<0,05)$. A segunda hipótese (H2 - O fator Relacionamento tem relação significativa e positiva com o comprometimento organizacional afetivo) também não se confirmou, conforme os resultados apresentados na seção anterior $(r=204$, não significativo). Os resultados mostraram que o estilo de liderança Relacionamento com os subordinados não tem relação significativa com o comprometimento afetivo dos colaboradores. A terceira hipótese $(\mathbf{H 3}$ - O estilo Situacional tem relação significativa e positiva com o comprometimento organizacional afetivo) foi a única hipótese validada, embora esse resultado também tenha sido pouco significativo no impacto sobre comprometimento organizacional afetivo $(r=0,209$ e $\mathrm{p}<0,05)$. 
Como as correlações foram fracas e sensíveis às diferentes amostras, conforme o teste de Bootstrap, nada se pode concluir sobre a influência dos estilos de liderança na relação com o comprometimento organizacional afetivo. Os resultados desta pesquisa demonstram que o comprometimento possui pouca relação com os estilos de liderança. Estudos como os de Souza (2011), Fernandes (2012) e Siqueira, Costa e Filenga (2012) sugerem que, independentemente do estilo de liderança adotado pelos líderes, o comprometimento afetivo do trabalhador passa por outras questões ligadas à organização, como, por exemplo, a percepção de suporte organizacional.

A revisão dos estudos recentes aponta para a liderança como forte influenciadora do sucesso, da continuidade e do desempenho organizacional, razão pela qual os avanços do conhecimento sobre o tema são fundamentais (CAVICCHIOLI, 2008; BENEVIDES, 2010), muito embora se saiba que outros fatores como os externos evidentemente impactam a organização.

Nos estudos analisados, as lideranças democráticas e transformacionais se destacam (GONÇALVES, 2008; SILVA, 2009; SANTOS, 2010; BENEVIDES, 2010; ROCHA; CAVALCANTE; SOUZA, 2011; ARAUJO, 2011), o que sugere que disciplina, inovação, capacidade de negociação (SILVA, 2009), habilidades de desenvolvimento das necessidades de autorrealização e de comprometimento que ultrapassem os interesses pessoais e aportem nos interesses grupais (BURNS, 1978) são algumas das características essenciais para se alcançar sucesso na liderança. Além disso, lideranças voltadas para os relacionamentos se mostram como ideais para se influenciar a comunicação e a cultura (ROVEDA, 2010). O fenômeno da globalização tem frequentemente exigido das organizações a promoção de mudanças fundamentais em tempos recordes. Naturalmente, isso exige das lideranças o cuidado com os seus liderados que, muitas vezes, não estão aptos a absorver e a reagir adequadamente às necessidades (maturidade). No entanto, pode-se considerar que, tão fundamental como se voltar para os relacionamentos, é voltar-se para a situação. Em dado momento, a tarefa apresenta-se como prioritária, e isso normalmente acontece em um contexto interno e externo repleto de desafios e contratempos. Fica posto, nesse caso, ao líder, a tarefa de lidar com as variáveis que influenciam os interesses da organização e dos seus liderados. Apesar de esta pesquisa ter identificado que o comprometimento organizacional afetivo possui pouca relação com os estilos de liderança, é preciso considerar que a análise se restringiu a um único ambiente empresarial, o que não descarta a possibilidade de que estudos mais abrangentes possam apresentar resultados diferentes, representando sua principal limitação. 
Os resultados apresentados contribuem, de maneira geral, para o aprimoramento dos processos de gestão de pessoas, sendo úteis para a área de Recursos Humanos, pois a promoção de melhorias no desenvolvimento das lideranças e no comprometimento das pessoas por meio das políticas da organização é sempre necessária.

Uma sugestão para estudos futuros é a análise conjunta do comprometimento organizacional afetivo com o estilo de liderança, sendo ambas preditoras de desempenho. Pois é reconhecido que o comprometimento afeta o desempenho, bem como o estilo de liderança, e uma vez que elas não têm relação entre si, saber o que é mais importante para melhorar o desempenho é algo de muita contribuição para a área de Gestão de Pessoas.

\section{REFERÊNCIAS}

ALLEN, N. J.; MEYER, J. P. The measurement and antecedents of affective, continuance and normative commitment to the organization. Journal of Occupational Psychology, v. 63, p. 01-18, 1990.

\section{ANDRADE, M. M. Como preparar trabalhos para o curso de Pós-} graduação: noções práticas. São Paulo: Atlas, 2002.

ARAUJO, A. Coach: um parceiro para o seu sucesso! Rio de Janeiro: Elsevier, 2011.

BARNEY, J. B. Asset stocks and sustained competitive advantage: a comment. Management Science, v. 35, p. 1511-1513, 1989.

BASTOS, A. V. B. Comprometimento organizacional: a estrutura dos vínculos do trabalhador com a organização, a carreira e o sindicato. 1994. 133 p. Tese (Doutorado em Administração)-Brasília, DF: Universidade de Brasília, 1994.

BENEVIDES, V. L. A. Os estilos de liderança e as principais táticas de influência utilizadas pelos líderes brasileiros. 2010. 144 p. Dissertação (Mestrado Executivo em Gestão Empresarial)-Fundação Getulio Vargas, São Paulo, 2010.

BERGAMINI, C. W. Liderança: administração do sentido. São Paulo: Atlas, 1994.

BLAKE, R. R.; MOUTON, J. S. O grid gerencial. São Paulo: Pioneira, 1975. 
BLANCO, V. B. Um estudo sobre a prática de coaching no ambiente organizacional e a possibilidade de sua aplicação como prática de gestão de conhecimento. 2006. 217p. Dissertação (Mestrado em Gestão do Conhecimento e Tecnologia da Informação)- Universidade Católica de Brasília, Brasília, DF, 2006.

BOWDITCH, J. L.; BUONO, A. F. Elementos do comportamento organizacional. São Paulo: Pioneira Thomson, 2002.

BURNS, J. M. Leadership. New York: Harper, 1978.

CAVICCHIOLI, G. Estilos de liderança de fundadores de empresas familiares do setor de transporte rodoviário de cargas no Brasil e a continuidade do negócio. 2008. 124p. Dissertação (Mestrado em Administração de empresas)-Pontifícia Universidade Católica de São Paulo, São Paulo, 2008.

CHANG JUNIOR, J. Gestão de pessoas através do desenvolvimento do comprometimento organizacional: uma abordagem holística e simultânea dos determinantes envolvidos nesse processo. 2002. Tese (Doutorado em Administração)-Universidade de São Paulo, São Paulo, 2002.

CONGER, J. A.; KANUNGO, R. N. Toward a behavioral theory of charismatic leadership in organizational settings. Academy of Management Review, v. 12, p. 637-647, 1987.

COSTA, F. M.; BASTOS, A. V. B. Múltiplos comprometimentos no trabalho: um estudo entre trabalhadores de organizações agrícolas do polo de fruticultura irrigada de Juazeiro/Petrolina. Rev. Adm. UFSM, Santa Maria, v. 2, n. 2, p. 280297, maio/ago. 2009.

DI STEFANO, R. O Líder-coach: líderes criando líderes. Rio de Janeiro: Qualitymark, 2012.

FERNANDES, M. C. O papel moderador de estilos de liderança na relação entre percepção de suporte organizacional e comprometimento organizacional afetivo: um estudo com trabalhadores da Região Sudeste do Brasil. 2012. 113 p. Dissertação (Mestrado em Administração)-Universidade Metodista de São Paulo, São Bernardo do Campo, 2012.

FRAGA, L. D. Motivação nas Organizações. Revista da Católica, v. 3, n. 5, jan./ jun. 2005.

FURTADO, O. Dialética e contradições da construção da identidade social.

Psicol. Soc., v. 22, n. 2, p. 259-268, 2010. 
GASPAR, D. J.; PORTÁSIO, R. M. Liderança e coaching: desenvolvendo pessoas, recriando organizações. Rev. de Ciências Gerenciais, v. 13, n. 18, p. 17-41, 2009.

GIL, A. C. Pesquisa Social. São Paulo: Atlas, 1999.

GOLEMAN, D. O poder da inteligência emocional: a experiência de liderar com sensibilidade e eficácia. Rio de Janeiro: Campus, 2002.

GONÇALVES, M. N. C. Estilos de liderança: um estudo de autopercepção de enfermeiros gestores. 2008. 141 p. Dissertação (Mestrado em Ciências Empresariais)-Universidade Fernando Pessoa, Porto, Portugal, 2008.

HAIR JUNIOR, J. F. et al. Análise multivariada de dados. 5. ed. Porto Alegre: Bookman, 2005.

HERSEY, P.; BLANCHARD, K. H. Psicologia para administradores: a teoria e as técnicas da liderança situacional. São Paulo: E.P.U., 1986.

LONGARAY, A. A.; GIESTA, L. C. Pressupostos para uma Direção Eficaz: a teoria de liderança revisitada. In: ENCONTRO NACIONAL DE ENGENHARIA DE PRODUÇÃO, 29; 1999, Salvador. Anais... Salvador: Abepro, 1999.

MAGALHÃES, L. R. Aprendendo a lidar com gente: relações interpessoais no cotidiano. 2. ed. Salvador: Edufba, 2001.

MAYER, J. D.; DIPAOLO, M. T.; SALOVEY, P. Perceiving affective content in ambiguous visual stimuli: a component of emotional intelligence. Journal of Personality Assessment, v. 54, p. 772-781, 1990.

McGREGOR, D. Motivação e Liderança. São Paulo: Brasiliense, 1973.

McGREGOR, D. O lado humano da empresa. São Paulo: Martins Fontes, 1980.

MEDEIROS, C. A. F. et al. Comprometimento Organizacional: o estado na arte no Brasil. RAC - Revista de Administração Contemporânea, v. 7, n. 4, p. 187-209, out./dez. 2003.

MELO, E. A. A. Escala de avaliação do estilo gerencial (EAEG): desenvolvimento e validação. Revista Psicologia: Organizações e Trabalho RPOT, v. 4, n. 2, p. 3132, 2004.

MEYER, J. P.; ALLEN, N. J. A three-component conceptualization of organizational commitment. Human Resource Management Review, v. 1, n. 1, p. 61-89, 1991. 
MOLLIS, M. Las reformas de la educación superior en Argentina para el nuevo milenio. Avaliação, Campinas, v. 13, n. 2, p. 509-532, 2008.

MOWDAY, R. T.; PORTER, L. W.; STEERS, R. M. Employee-organization linkages: the psychology of commitment, absenteeism, and turnover. New York: Academic Press, 1982.

MOWDAY, R. T.; PORTER, L. W.; STEERS, R. M. The measurement of organizational commitment. Journal of Vocational Behavior, v. 14, p. 224-247, 1979.

PANTOJA, S. G. Liderança: uma relação eficaz. 2005. 162 p. Dissertação (Mestrado em Engenharia Mecânica)-Universidade Estadual de Campinas. Campinas, 2005.

PENROSE, E.; PITELIS, C. The theory of the growth of the firm. 4. ed. New York: Oxford, 1959.

POLIT, D. F.; BECK, C. T.; HUNGLER, B. P. Fundamentos de pesquisa em Enfermagem: métodos, avaliação e utilização. Tradução Ana Thorell. 5. ed. Porto Alegre: Artmed, 2004.

PORTER, M. E. Competitive strategy: techniques for analyzing industries and competitors. New York: The Free Press, 1980.

RAUPP, F. M.; BEUREN, I. M. Metodologia da pesquisa aplicável às ciências sociais. In: BEUREN, I. M. (Org.). Como elaborar trabalhos monográficos em contabilidade: teoria e prática. São Paulo: Atlas, 2006.

RICHARDSON, R. J. Pesquisa social: métodos e técnicas. São Paulo: Atlas, 1999.

RIOS, A. L. F. As Relações entre Satisfação, Longevidade no Trabalho e Comprometimento Organizacional em uma Empresa do Segmento Metalúrgico de Fortaleza. Revista de Psicologia UFC, v. 2, n. 1, jan./jun. 2011.

ROCHA, D.; CALVANTE, C. E.; SOUZA, W. J. Estilos de Liderança: estudo de caso em uma organização militar. Revista de Administração da UNIMEP, v. 2, n. 1, jan./jun. 2011.

ROMAN, S. et al. Análise do Comprometimento Organizacional de Sua Natureza em Relação aos Funcionários Públicos Municipais. Gestão \& Regionalidade, v. 28, n. 84, p. 5-19, set./dez. 2012. 
ROSENSTOCK, K. I. V. Satisfação, envolvimento e comprometimento com o trabalho: percepção dos profissionais na estratégia saúde da família. Revista Baiana de Saúde Pública, v. 35, n. 3, p. 591-603, 2011.

ROVEDA, V. As inter-relações entre liderança, comunicação e cultura nas organizações. 2010. 418 p. Dissertação (Mestrado em Administração)Universidade Caxias do Sul, Caxias do Sul, 2010.

\section{SANTOS, T. L. Os estilos de liderança nas organizações não} governamentais da região metropolitana de Belém. 2010. 109 p. Dissertação (Mestrado Interinstitucional em Administração)-Universidade Federal do Rio Grande do Norte, Natal, 2010.

SCHERMERHORN JUNIOR, J. R.; HUNT, J. G.; OSBORN, R. N. Fundamentos do comportamento organizacional. 2. ed. São Paulo: Bookmann, 2005.

SILVA, J. C. O estilo de liderança dos bibliotecários de Brasília. 2009. 169 p. Dissertação (Mestrado em Ciência da Informação)-Universidade de Brasília, Brasília, DF, 2009.

SIQUEIRA, M. M. M.; COSTA, L. V.; FILENGA, D. O poder preditivo de percepção de justiça sobre suporte organizacional e seu impacto sobre o comprometimento afetivo. Gestão Contemporânea, Porto Alegre, v. 9, n. 12, p. 235-256, jul./dez. 2012.

SIQUEIRA, M. M. M. Medidas de comportamento organizacional: ferramentas de diagnóstico e de gestão. Porto Alegre: Artmed, 2008.

SOUZA, W. S. Análise da interdependência do capital psicológico, percepções de suporte e bem-estar no trabalho. 2011. Dissertação (Mestrado em Administração)-Universidade Metodista de São Paulo, São Bernardo do Campo, 2011.

STEFANO, S. R.; GOMES FILHO, A. C. Estilos de liderança: um estudo comparativo entre as empresas de transporte. In: ENCONTRO DA ANPAD ENANPAD, 27., 2003, Atibaia. Anais... Atibaia, 2003.

TABACHNICK, B. G.; FIDELL, L. S. Using multivariate statistics. 2. ed. New York: HarperCollins, 2001.

URIS, A. Liderança. 2. ed. São Paulo: IBRASA, 1967.

WANDERLEY, L. E. São Paulo no contexto da globalização. Lua Nova, n. 69, p. 173-203, 2006. 
ZANELLI, J. C.; BORGES-ANDRADE, J. E.; BASTOS, A. V. B. Psicologia, organizações e trabalho no Brasil. Porto Alegre: Artmed, 2004.

\section{Como citar este artigo:}

NOGUEIRA, Maria de Lourdes de Oliveira; COSTA, Luciano Venelli; - CLARO, José Alberto Carvalho dos Santos. Relação entre estilo de liderança Z e comprometimento organizacional afetivo. RACE, Revista de Administração, \& Contabilidade e Economia, Joaçaba: Ed. Unoesc, v. 14, n. 2, p. 707-736, maio/ago. 2015. Disponível em: < http://editora.unoesc.edu.br/index.php/race>. Acesso em: dia/mês/ano.

Nogueira, M. de L. de O., Costa, L. V., \& Claro, J. A. C. dos S. (2015). Relação entre estilo de liderança e comprometimento organizacional afetivo. RACE, Revista $\underset{z}{\varangle}$ de Administração, Contabilidade e Economia, 14(2), 707-736. Recuperado em dia/mês/ ano, de http://editora.unoesc.edu.br/index.php/race 
